\title{
Knowledge and Attitudes in Regard to Pandemic Influenza A (H1N1) in a Multiethnic Community of Malaysia
}

\author{
Li Ping Wong • I-Ching Sam
}

Published online: 11 September 2010

(C) International Society of Behavioral Medicine 2010

\begin{abstract}
Background Assessment of general public's knowledge and attitudes toward the development and prevention of new disease outbreaks is imperative because they have profound effects on health behaviors and may contribute to the control of the epidemic.

Purpose To investigate the level of knowledge and attitudes towards the influenza $\mathrm{A}(\mathrm{H} 1 \mathrm{~N} 1)$ outbreak across various ethnic groups and socio-demographic backgrounds in Malaysia.

Method A cross-sectional, population-based, computerassisted telephone interview exploring knowledge and attitudes regarding influenza $\mathrm{A}(\mathrm{H} 1 \mathrm{~N} 1)$ was conducted in Malaysia. Between July 11 and September 12, 2009, a total of 1,050 respondents were interviewed (response rate 69.3\%). Results The mean total knowledge score for the overall sample was $7.30(\mathrm{SD} \pm 1.961)$ out of a possible score of 13 (Chinese had the highest scores, followed by Indians, then Malays). Some erroneous beliefs about the modes of transmission were identified. The majority of the participants $(73.8 \%)$ perceived the $\mathrm{A}(\mathrm{H} 1 \mathrm{~N} 1)$ infection as often deadly. Despite the overestimation of the severity of A (H1N1) infection, high confidence in preventing infection and low perceived susceptibility of infection were reported. Influenza A(H1N1)-related stigma was prevalent and exhibited differences across ethnic groups.
\end{abstract}

\section{P. Wong $(\triangle)$}

Medical Education and Research Development Unit, Faculty of Medicine, University of Malaya,

50603 Kuala Lumpur, Malaysia

e-mail: wonglp@ummc.edu.my

I.-C. Sam

Tropical Infectious Diseases Research and Education Centre,

Department of Medical Microbiology, Faculty of Medicine,

University of Malaya,

50603 Kuala Lumpur, Malaysia
Conclusions Findings suggest that provision of education and clear information are essential to correct the misconceptions, and increase perceived susceptibility to infection so that the general public will take precautions against $\mathrm{A}$ (H1N1) infection.

Keywords Knowledge $\cdot$ Attitudes $\cdot$ Influenza A(H1N1)

\section{Introduction}

In April 2009, a new strain of human influenza A(H1N1) virus appeared in Mexico, and has spread rapidly around the world, causing the first pandemic for 40 years. Malaysia confirmed its first case of influenza A(H1N1) on May 15, 2009. In response to increasing local transmission, Malaysia moved from containment to mitigation stage on July 9, 2009 [1]. Since then, the $\mathrm{A}(\mathrm{H} 1 \mathrm{~N} 1)$ pandemic has grown exponentially. On July 23, 2009, approximately 2 weeks after the commencement of this study, the first death from influenza A(H1N1) was reported. On September 13, 2009, the date on which our data collection finished, the total fatality count was 74 [2].

Public knowledge and attitudes of past outbreaks, such as SARS and avian influenza, have been studied in many Western [3-5] and Asian countries [6-10]. It is imperative to assess the general public's knowledge and attitudes of the development and prevention of new disease outbreaks [9, 11]. During the SARS epidemic, public perceptions affected health behaviors such as handwashing and wearing face masks, which in turn contributed to the control of the epidemic [11, 12]. In both the SARS and H5N1 avian influenza outbreaks, public fear and level of distress was associated with perceptions and knowledge $[8,13]$.

Currently, there are few studies on knowledge and perceptions of the new influenza $\mathrm{A}(\mathrm{H} 1 \mathrm{~N} 1)$ epidemic. A 
recent study in Hong Kong showed inadequate knowledge among the general public and misconceptions in the modes of transmission of A(H1N1) [14]. Another study conducted in the UK in the early stage of the pandemic showed that risk perception and perceived seriousness of the influenza $\mathrm{A}(\mathrm{H} 1 \mathrm{~N} 1)$ were associated with the practice of recommended health behaviors [15]. An internet-based survey, conducted during WHO pandemic stage 5 , revealed that emotional concerns about infection were significant predictors of behavioral responses to the H1N1 pandemic [16].

In the immediacy of the new emerging $A(H 1 N 1)$ influenza virus, we conducted a baseline survey to examine knowledge, attitudes, psychosocial consequences, and impact of the pandemic in Malaysia. Of note, the survey was carried out over a period of escalating reported deaths, generating much public and media concern. Malaysia is a fast-developing country in Southeast Asia with a population of 27.7 million, which encompasses a majority Malay (50.8\%) and other ethnic groups, mainly Chinese (23.0\%), non-Malay bumiputra (11.0\%), and Indian (6.9\%) [17]. Each ethnic group has its own culture and religions. This multiethnic, multi-religious society allow for a diverse exploration of cultural variation in expression of attitudes and perceptions towards the new $\mathrm{A}(\mathrm{H} 1 \mathrm{~N} 1)$ pandemic. The aim of this study was to investigate the level of knowledge and attitudes towards the influenza $\mathrm{A}(\mathrm{H} 1 \mathrm{~N} 1)$ outbreak across various ethnic groups and socio-demographic backgrounds.

\section{Methods}

Sample

A cross-sectional, population-based, computer-assisted telephone interview (CATI) survey was carried out between July 11 and September 12, 2009. The study population comprised Malaysian adults randomly sampled from the latest electronic version (2008/2009) of the residential telephone directory of Selangor state and the Federal Territory of Kuala Lumpur. Kuala Lumpur, the capital city and federal territory of Malaysia, has a population of 1,629,400, and covers an area $243 \mathrm{~km}^{2}$. The state of Selangor surrounds the capital city of Kuala Lumpur, has a population of 5,017,100 and an area of $8,154 \mathrm{~km}^{2}$. One person aged 18 years and older from each household was randomly selected and invited to participate. Interviews were conducted between 5:30 p.m. and 10:00 p.m. on weekdays and from 12:00 p.m. to 7.00 p.m. on weekends or public holidays to avoid over-representation of unemployed participants. Unanswered numbers were called at least two more times on separate days before being regarded as uncontactable.

The sample was stratified by the three main ethnic groups in the Malaysian population, Malays, Chinese, and Indians. The Chinese and Indians were slightly over- sampled to assure that analyses of disparities could be conducted with sufficient statistical power for each of the ethnic groups.

\section{Instrument}

On the knowledge assessment section of the questionnaire, each respondent was first asked to list the symptoms of influenza $\mathrm{A}(\mathrm{H} 1 \mathrm{~N} 1)$. A score of 1 was given for each correctly identified symptom. The subsequent knowledge questions (six items) were posed in which the answers were either Yes, No, or Don't know. A score of 1 was assigned to a correct answer and a value of 0 to an incorrect answer or Don't know responses. Questions on perception were divided into two parts. The first part explored perceived susceptibility towards influenza $\mathrm{A}(\mathrm{H} 1 \mathrm{~N} 1)$ (three items), in which participants indicated their level of susceptibility on a four-point Likert-type scale (very high, high, low, very low). The second part examined A(H1N1)-related stigma (six items), with answers of either Yes or No. Demographic questions (nine items) were asked after completion of the survey questions.

The survey questions were adapted and modified from previous published literature [3-12]. The questionnaires were in three languages: Bahasa Malaysia (the national language), English, and Chinese. A team of trained multiethnic interviewers performed the interviews; each of the ethnic group interviewers was assigned to interview respondents of a similar ethnic group. In the pilot study, interviews were conducted with 20 various ethnicity respondents from the telephone directory. The test respondents commented that the questions were easily understood, and the average completion time was $15 \mathrm{~min}$. Informed consent was obtained verbally. Respondents were assured that their responses would be confidential and reminded that their participation in the interview was voluntary. The study was approved by the Medical Ethics Committee, University Malaya Medical Center, Kuala Lumpur, Malaysia.

\section{Analyses}

All statistical analyses were performed using SPSS version 17.0 for Windows software (SPSS, Inc., Chicago, IL, USA). Non-response and irrelevant (non-applicable) responses (for example, questions regarding pork and pork products to Muslim respondents) were treated as missing values and, therefore, excluded from the analyses. $T$ tests and one-way analysis of variance (ANOVA) were used for comparisons of means; the chi-squared test was used to test the significance of differences in percentages. Post hoc comparisons using the Tukey's HSD test were conducted to evaluate pairwise differences among the means. Multiple linear regression analysis using the enter method was 
carried out to explore relationships between knowledge scores and socio-demographic variables that had a $P$ value less than 0.10 in bivariate comparisons. Multivariate logistic regression analyses were used to determine factors associated with perceived susceptibility to $\mathrm{A}(\mathrm{H} 1 \mathrm{~N} 1)$, and perceived confidence in $\mathrm{A}(\mathrm{H} 1 \mathrm{~N} 1)$ prevention. A backward stepwise logistic regression selection method was carried out to select significant independent variables and make adjustments for covariates among variables. Wald chisquared statistics were used to test the significance of individual coefficients in the model. Goodness of fit was assessed with the Hosmer-Lemeshow test. Statistical significance was set to $P<0.05$.

\section{Results}

\section{Participants' Characteristics}

Figure 1 provides the flowchart of the CATI process. A total of 6,230 call attempts were made, resulting in 1,050 $(16.9 \%)$ responding households. The low response rate was due to the large number of uncontactable households. However, of the total successful calls $(1,750), 60.0 \%$ ( $n=$ $1,050)$ completed the interview. By ethnic group, the proportions that completed interview upon successful calls were $64.8 \%$ (436/673), 52.3\% (352/673), and 64.8\% (262/ 404) for Malay, Chinese, and Indian samples, respectively. Table 1 shows socio-demographic characteristics of the 1,050 respondents in the survey. The majority of respondents in this sample were Malays (41.5\%), followed by Chinese (33.5\%) and Indians (25.0\%).
Knowledge

The majority was able to name three $(33.2 \%)$ or four $(25.6 \%)$ influenza-like illness symptoms, and only a total of 23 respondents $(2.2 \%)$ were unable to name even one of the symptoms. A fifth of respondents (20.4\%) were able to name only one to two symptoms. As shown in Table 2, fever, running nose, and coughing were the three most commonly identified symptoms of influenza A(H1N1). Half of the respondents $(50.4 \%)$ could not identify the symptom of sore throat.

The six-item close-ended knowledge questions had an inter-item correlation range of -0.043 to 0.203 with Cronbach's alpha of 0.233 . A considerable number of participants $(n=329,31.3 \%)$ erroneously believed that the $\mathrm{A}(\mathrm{H} 1 \mathrm{~N} 1)$ influenza can be transmissible to people through eating improperly cooked pork and pork products, the majority of whom were of Malay ethnicity $47.8 \%$, followed by Indians (31.5\%), and the lowest were the Chinese $(13.7 \%)\left[\chi^{2}(5\right.$, $1030)=199.60, P<0.001]$. With regard to the severity of influenza $\mathrm{A}(\mathrm{H} 1 \mathrm{~N} 1)$, a considerable number of participants had the misconception that $\mathrm{A}(\mathrm{H} 1 \mathrm{~N} 1)$ infection is often deadly (73.8\%). More specifically, people who were female, Malay, employed, had a high income, graduated from university, and living in urban areas were more likely to perceive that $\mathrm{A}(\mathrm{H} 1 \mathrm{~N} 1)$ infection is often deadly $(P<0.01)$.

The mean total knowledge score for the overall sample was $7.30(\mathrm{SD} \pm 1.961)$ out of a possible score of 13 . Statistically significant differences in the mean total knowledge score were observed among ethnic groups, gender, education attainment, employment status, average household income, and locality (Table 3). Multiple linear
Fig. 1 Illustration of the CATI process of the survey

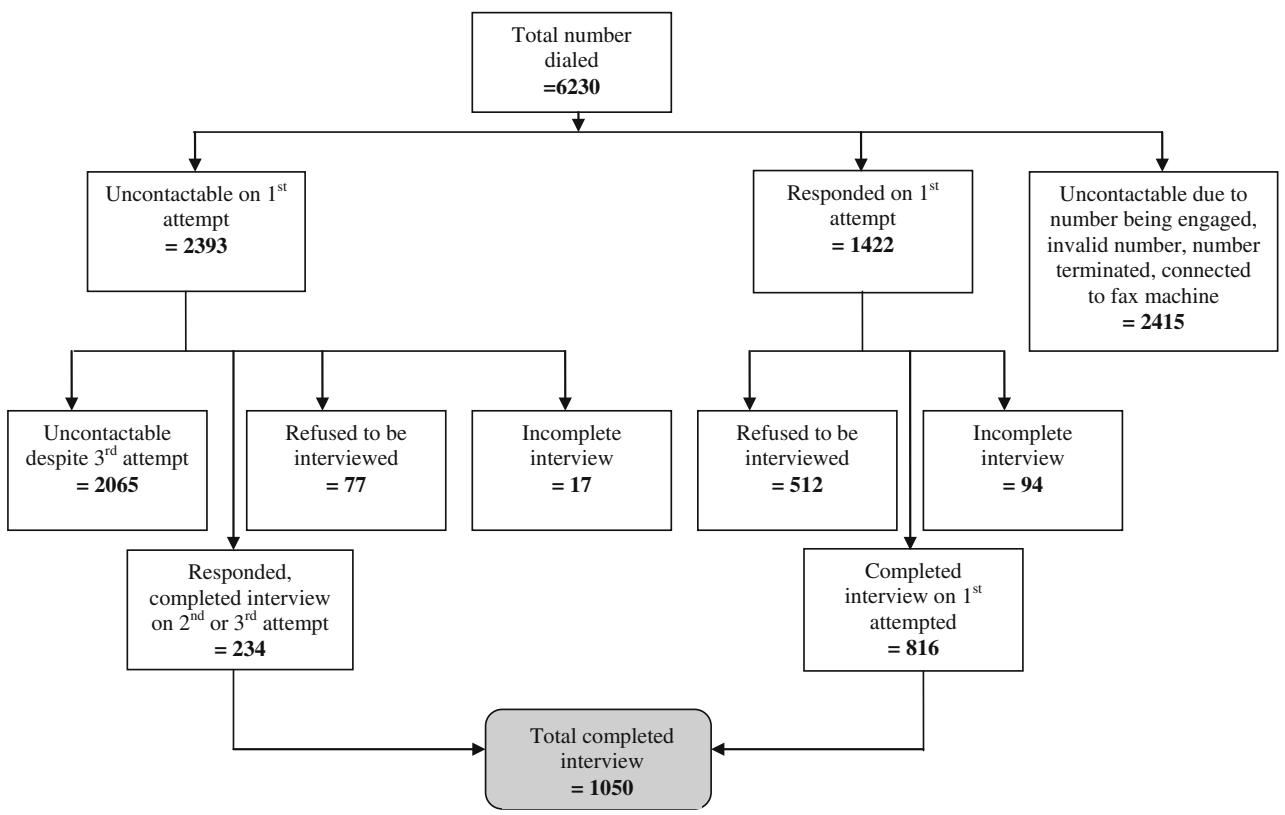


Table 1 Socio-demographic characteristics of respondents $(N=1,050)$

\begin{tabular}{|c|c|c|}
\hline \multirow[t]{2}{*}{ Socio-demographic variables } & \multicolumn{2}{|c|}{ Total sample } \\
\hline & $N$ & $\%$ \\
\hline \multicolumn{3}{|l|}{ Gender } \\
\hline Male & 379 & 36.1 \\
\hline Female & 671 & 63.9 \\
\hline \multicolumn{3}{|l|}{ Ethnicity } \\
\hline Malay & 436 & 41.5 \\
\hline Chinese & 352 & 33.5 \\
\hline Indian & 262 & 25.0 \\
\hline \multicolumn{3}{|l|}{ Religion } \\
\hline Muslim & 440 & 41.9 \\
\hline Buddhist & 249 & 23.7 \\
\hline Taoist & 17 & 1.6 \\
\hline Hindu & 236 & 22.5 \\
\hline Sikh & 2 & 0.2 \\
\hline Christian & 78 & 7.4 \\
\hline No religion & 21 & 2.0 \\
\hline Others & 7 & 0.7 \\
\hline \multicolumn{3}{|l|}{$\operatorname{Age}^{\mathrm{a}}$} \\
\hline $18-39$ & 532 & 51.1 \\
\hline $40-59$ & 455 & 43.7 \\
\hline $60-79$ & 54 & 5.2 \\
\hline \multicolumn{3}{|l|}{ Highest education attainment } \\
\hline No formal schooling & 6 & 0.6 \\
\hline Primary school & 59 & 5.6 \\
\hline Secondary school & 452 & 43.0 \\
\hline University & 533 & 50.8 \\
\hline \multicolumn{3}{|l|}{ Occupation $^{\mathrm{a}}$} \\
\hline Self-employed & 62 & 5.9 \\
\hline Professional and managerial & 325 & 31.0 \\
\hline Skilled workers & 146 & 13.9 \\
\hline Unskilled workers & 67 & 6.4 \\
\hline Housewife & 229 & 21.9 \\
\hline Student & 137 & 13.1 \\
\hline Unemployed and retired & 81 & 7.7 \\
\hline \multicolumn{3}{|c|}{ Average monthly household income ${ }^{a}$} \\
\hline$<2,000$ & 229 & 22.5 \\
\hline $2,001-4,000$ & 378 & 37.2 \\
\hline$>4,001$ & 410 & 40.3 \\
\hline \multicolumn{3}{|l|}{ Locality } \\
\hline Urban & 838 & 79.8 \\
\hline Suburban & 123 & 11.7 \\
\hline Rural & 89 & 8.5 \\
\hline
\end{tabular}

All values are based on participants self-reporting

${ }^{a}$ Number of respondents less than 1,050 (total respondent) due to non-response regression analysis show that gender, ethnicity, education, household income, and urban/rural locality significantly predict level of $\mathrm{A}(\mathrm{H} 1 \mathrm{~N} 1)$ knowledge. The adjusted $R^{2}$ for this model is 0.12 , which implies that the model explains $12 \%$ of the variability. The regression model was highly significant, $F(11,995)=12.997, P<0.001$.

\section{Perceived Susceptibility and Confidence in Prevention}

Table 4 shows that $64.5 \%$ and $67.2 \%$ of the respondents, respectively, rated perceived susceptibility and perceived family members' susceptibility to $\mathrm{A}(\mathrm{H} 1 \mathrm{~N} 1)$ infection as "low" or "very low". The majority (73.0\%) were also "very confident" or "quite confident" in preventing themselves from getting $\mathrm{A}(\mathrm{H} 1 \mathrm{~N} 1)$. Figure 2 shows the temporal trends for all responses to "very" and "quite" confident in prevention and "very high" and "high" perceived susceptibility to infection. The first death was reported 2 weeks after the commencement of this study, and increased steadily and reached a peak in week 6 , before a rapid decline. The levels of perception of "very high" and "high" susceptibility to infection did not vary significantly over the study period. In contrast, rates of those who were "very" and "quite" confident in prevention of H1N1 infection decreased significantly as the number of reported deaths increased. As indicated in Table 5, univariate analysis showed that significantly more males (39.6\%) than females $(33.2 \%)$ perceived very high/high susceptibility to A (H1N1) infection. High perceived susceptibility to A (H1N1) infection was inversely related to age. Respondents with higher education, who were employed, and living in urban areas had significantly higher perceived susceptibility to $\mathrm{A}(\mathrm{H} 1 \mathrm{~N} 1)$ infection. Respondents with higher knowledge scores indicated higher perceived self susceptibility to A (H1N1) infection. In the multiple logistic regression analyses, significant predictors for high susceptibility to A (H1N1) infection were ages $18-39$ years $(\mathrm{OR}=2.37$, vs. being $60-79$ years), ages $40-59$ years $(\mathrm{OR}=2.12$, vs. being 60-79 years), household income RM2,001-4,000 (OR 1.47 , vs. $>\mathrm{RM} 4,000)$, and residing in urban areas $(\mathrm{OR}=$ 1.62 , vs. suburban). The overall logistic model is highly significant according to the Model chi-square statistic (chisquare $=37.80, \mathrm{df}=12, P<0.0001)$.

With regard to perceived confidence of preventing A (H1N1) infection, females were more confident than male respondents. Highly significant differences between the three ethnic groups was found; Malay respondents reported the highest levels of perceived confidence in prevention of $\mathrm{A}(\mathrm{H} 1 \mathrm{~N} 1)$, followed by the Indians and Chinese. Older respondents reported higher confidence of prevention. Multiple logistic regression suggested that respondents were more likely to have high perceived confidence in prevention of $\mathrm{A}(\mathrm{H} 1 \mathrm{~N} 1)$ if they were female $(\mathrm{OR}=1.61$, vs. 


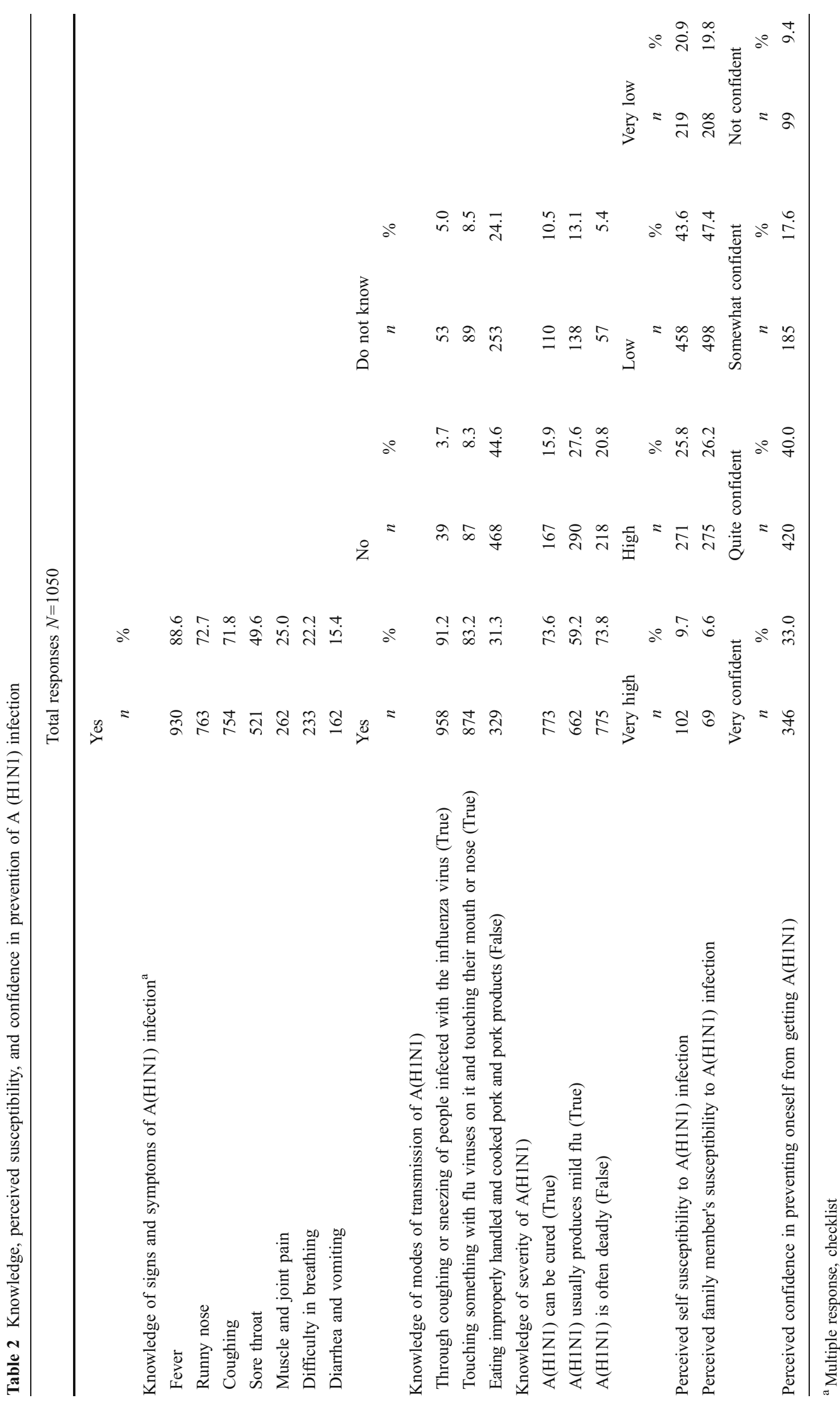


Table 3 Socio-demographic differences in mean knowledge score and multiple linear regression analysis of socio-demographic variables predicting knowledge of $\mathrm{A}(\mathrm{H} 1 \mathrm{~N} 1)$

\begin{tabular}{|c|c|c|c|c|}
\hline \multirow{2}{*}{$\begin{array}{l}\text { Socio-demographic } \\
\text { variables }\end{array}$} & \multicolumn{3}{|c|}{ Total knowledge (0-13-items scale) } & \multirow{2}{*}{$\begin{array}{l}\text { Linear regression model }{ }^{\mathrm{a}} F(11,995)=12.997 \\
P<0.001 \text {, adjusted } R^{2}=0.123 \\
\beta \text { (SE) }\end{array}$} \\
\hline & $N^{\mathrm{b}}$ & Mean \pm SD & $P$ & \\
\hline \multicolumn{5}{|l|}{ Gender } \\
\hline Male & 379 & $7.03 \pm 2.01$ & $P=0.001$ & $-0.56(0.13)^{* *}$ \\
\hline Female & 671 & $7.46 \pm 1.92$ & $F(1,1048)=11.39$ & - \\
\hline \multicolumn{5}{|l|}{ Ethnicity } \\
\hline Malay & 436 & $6.72 \pm 1.61$ & $P<0.001$ & $-0.61(1.55)^{* *}$ \\
\hline Chinese & 352 & $7.97 \pm 2.03$ & $F(2,1047)=42.75$ & $0.59(0.16)^{* *}$ \\
\hline Indian & 262 & $7.38 \pm 2.11$ & & - \\
\hline \multicolumn{5}{|l|}{ Age } \\
\hline $18-39$ & 532 & $7.35 \pm 2.05$ & $P=0.621$ & $-0.20(0.28)$ \\
\hline $40-59$ & 455 & $7.25 \pm 1.85$ & $F(2,1038)=0.476$ & $-0.16(0.28)$ \\
\hline $60-79$ & 54 & $7.17 \pm 2.06$ & & - \\
\hline \multicolumn{5}{|c|}{ Highest education attainment } \\
\hline Tertiary education & 533 & $7.55 \pm 1.89$ & $P=0.000$ & $0.33(0.14)^{*}$ \\
\hline Secondary education & 517 & $7.06 \pm 2.01$ & $F(1,1048)=16.62$ & - \\
\hline \multicolumn{5}{|l|}{ Employment } \\
\hline Employed & 600 & $7.41 \pm 2.00$ & $P=0.049$ & $0.12(0.13)$ \\
\hline Not employed & 447 & $7.17 \pm 1.90$ & $F(1,1045)=3.87$ & - \\
\hline \multicolumn{5}{|c|}{ Average monthly household income } \\
\hline$<\mathrm{RM} 2000$ & 229 & $6.70 \pm 1.75$ & $P=0.000$ & $-0.65(0.18)^{* *}$ \\
\hline RM2001-4000 & 378 & $7.39 \pm 2.13$ & $F(2,1014)=13.57$ & $-0.12(0.14)$ \\
\hline$>$ RM4001 & 410 & $7.51 \pm 1.85$ & & - \\
\hline \multicolumn{5}{|l|}{ Locality } \\
\hline Urban & 838 & $7.40 \pm 1.92$ & $P=0.000$ & $0.41(0.22)^{*}$ \\
\hline Suburban & 123 & $7.24 \pm 1.98$ & $F(2,1047)=8.81$ & $0.37(0.27)$ \\
\hline Rural & 89 & $6.49 \pm 2.12$ & & - \\
\hline
\end{tabular}

${ }^{a}$ Respondents with missing information on a covariate were excluded from the regression model. The final regression models included 1,006 respondents with complete covariate information (knowledge)

${ }^{\mathrm{b}}$ Subtotals may vary owing to missing data

${ }^{*} P<0.05 ;{ }^{* *} P<0.001$

being male), Chinese ethnicity ( $\mathrm{OR}=0.39$, vs. being Indian), ages $18-39$ years $(\mathrm{OR}=0.33$, vs. being 60 79 years), ages $40-59$ years (OR $=0.40$, vs. being 60 79 years). The overall model was highly significant (chi-square $=64.83, \mathrm{df}=12, P<0.0001$ ). The Hosmer and Lemeshow tests indicated that both regression models had very good fit (Table 4).

\section{Stigma Related to $\mathrm{A}(\mathrm{H} 1 \mathrm{~N} 1)$}

The internal consistency of the six-item stigma related to A (H1N1) questions, evaluated by Cronbach's alpha was 0.632 , inter-item correlation ranged from 0.110 to 0.389 . The mean number of stigma was 1.94 (mode 1, median 2) out of a maximum of 6 . As indicated in Table 5 , three most commonly reported stigmas were: "Afraid to be in contact with people with flu symptoms" (60.8\%), "Afraid to be in contact with people who have just returned from overseas" (54.1\%), and "Afraid of visiting hospitals" (36.2\%). A minority indicated fear of eating pork and pork products (7.2\%). Some erroneously related the outbreak with avian influenza and expressed fear of eating birds (chicken) and bird products $(7.3 \%)$. There were significant differences in the responses to stigma items among the three ethnic groups studied. On the whole, the stigmatizing responses were more common among Malay ethnicity except for "Afraid of visiting hospitals". Among those that believed the $\mathrm{A}(\mathrm{H} 1 \mathrm{~N} 1)$ infection to be often deadly, more than half $(53.2 \%)$ were not "Afraid to be in contact with people with flu symptoms", two thirds $(67.0 \%)$ were not "Afraid to be in contact with people who have just returned from overseas" 
Table 4 Socio-demographic differences in perceived susceptibility and confidence in prevention of A (H1N1) infection

\begin{tabular}{|c|c|c|c|c|c|c|c|c|c|}
\hline \multirow{3}{*}{$\begin{array}{l}\text { Predictor } \\
\text { variable }\end{array}$} & \multicolumn{5}{|c|}{ Perceived self susceptibility to A (H1N1) infection } & \multicolumn{4}{|c|}{ Perceived confidence in prevention from A (H1N1) } \\
\hline & \multirow[t]{2}{*}{$N^{\mathrm{a}}$} & \multicolumn{2}{|c|}{$\begin{array}{l}\text { Percentage of } \\
\text { respondents }\end{array}$} & \multirow{2}{*}{$\begin{array}{l}\chi^{2} \\
P\end{array}$} & \multirow{2}{*}{$\begin{array}{l}\text { Logistic regression } \\
\text { model } N=1,007 \\
\text { OR }(95 \% \mathrm{CI})\end{array}$} & \multicolumn{2}{|c|}{ Percentage of respondents } & \multirow{2}{*}{$\begin{array}{l}\chi^{2} \\
P\end{array}$} & \multirow{2}{*}{$\begin{array}{l}\text { Logistic regression } \\
\text { model } N=1,007 \\
\text { OR }(95 \% \mathrm{CI})\end{array}$} \\
\hline & & $\begin{array}{l}\text { Very high/ } \\
\text { high }\end{array}$ & $\begin{array}{l}\text { Low/ } \\
\text { very low }\end{array}$ & & & $\begin{array}{l}\text { Very/quite } \\
\text { confident }\end{array}$ & $\begin{array}{l}\text { Somewhat/ } \\
\text { not confident }\end{array}$ & & \\
\hline \multicolumn{10}{|l|}{ Gender } \\
\hline Male & 379 & 39.6 & 60.4 & $0.023^{*}$ & NS & 69.1 & 30.9 & $0.036^{*}$ & $0.62(0.45,0.85) * *$ \\
\hline Female & 671 & 33.2 & 66.8 & & Reference & 75.1 & 24.9 & & Reference \\
\hline \multicolumn{10}{|l|}{ Ethnicity } \\
\hline Malay & 436 & 35.6 & 64.4 & 0.40 & & 80.5 & 19.5 & $<0.001 * * *$ & $1.14(0.76,1.72)$ \\
\hline Chinese & 352 & 33.2 & 66.8 & & NS & 60.2 & 39.8 & & $0.39(0.26,0.58) * * *$ \\
\hline Indian & 262 & 28.5 & 61.5 & & Reference & 77.5 & 22.5 & & Reference \\
\hline \multicolumn{10}{|l|}{ Age } \\
\hline $18-39$ & 532 & 38.3 & 61.7 & $0.011^{*}$ & $2.37(1.14,4.97)^{*}$ & 70.7 & 29.3 & $0.027 *$ & $0.33(0.14,0.77)^{* *}$ \\
\hline $40-59$ & 455 & 34.1 & 65.9 & & $2.12(1.02,4.41)^{*}$ & 74.3 & 25.7 & & $0.40(0.17,0.93)^{*}$ \\
\hline $60-79$ & 54 & 18.5 & 81.5 & & Reference & 87.0 & 13.0 & & Reference \\
\hline \multicolumn{10}{|c|}{ Highest education attainment } \\
\hline Tertiary & 533 & 39.4 & 60.6 & $0.005^{* *}$ & NS & 73.7 & 26.3 & 0.56 & NS \\
\hline Secondary & 517 & 31.5 & 68.5 & & Reference & 72.1 & 27.9 & & Reference \\
\hline \multicolumn{10}{|l|}{ Employment } \\
\hline Employed & 600 & 39.2 & 60.8 & $0.002 * *$ & NS & 72.7 & 27.3 & 0.79 & NS \\
\hline Not employed & 447 & 30.4 & 69.6 & & Reference & 73.4 & 26.6 & & Reference \\
\hline \multicolumn{10}{|c|}{ Average monthly household income } \\
\hline$<$ RM 2000 & 229 & 32.3 & 67.7 & & NS & 70.3 & 29.7 & 0.36 & NS \\
\hline RM 2001-4000 & 378 & 38.6 & 61.4 & 0.252 & $1.47(1.06,2.03)^{*}$ & 72.5 & 27.5 & & NS \\
\hline$>$ RM 4001 & 410 & 34.6 & 65.4 & & Reference & 75.4 & 24.6 & & Reference \\
\hline \multicolumn{10}{|l|}{ Locality } \\
\hline Urban & 383 & 37.6 & 62.4 & $0.024 *$ & $1.62(1.06,2.49)^{*}$ & 73.5 & 26.5 & & NS \\
\hline Rural & 123 & 27.0 & 73.0 & & NS & 69.7 & 30.3 & 0.69 & Reference \\
\hline Suburban & 89 & 27.6 & 72.4 & & Reference & 71.5 & 28.5 & & \\
\hline $\begin{array}{l}\text { Knowledge score } \\
(x \pm \mathrm{SD})\end{array}$ & 1050 & $7.47 \pm 1.89$ & $7.21 \pm 2.10$ & $0.037^{\mathrm{b}} *$ & NS & $7.26 \pm 1.93$ & $7.42 \pm 2.04$ & $0.27^{\mathrm{b}}$ & NS \\
\hline
\end{tabular}

Model 1 Perceived susceptibility; Hosmer and Lemeshow test, $\chi^{2}(8)=2.234, P=0.973$

Model 2 Confidence in prevention; Hosmer and Lemeshow test, $\chi^{2}(8)=12.510, P=0.130$

${ }^{\text {a }}$ Subtotals may vary owing to missing data

${ }^{\mathrm{b}} t$ test; $F$ value (df) $P$ value

$* P<0.05 ; * * P<0.01 ; * * * P<0.001$

\section{Discussion}

The majority of respondents were able to recognize the three common influenza-like illness namely fever, runny nose, and cough. However, less than half were able to name the symptom of sore throat. A considerable minority of respondents that was unable to name even one symptom was of concern. Although many knew of the mode of transmission of influenza $\mathrm{A}(\mathrm{H} 1 \mathrm{~N} 1)$, transmission via eating improperly handled and cooked pork and pork products was misperceived by a sizable minority of respondents.
This was likely due to the frequent references of $\mathrm{A}(\mathrm{H} 1 \mathrm{~N} 1)$ virus as "swine flu" in the early stages of the pandemic. Compared to a recent Hong Kong study [14], more respondents in Malaysia thought that $\mathrm{A}(\mathrm{H} 1 \mathrm{~N} 1)$ could be transmitted by eating pork products $(31.3 \%$, vs. $6.9 \%)$, more did not know that the $\mathrm{A}(\mathrm{H} 1 \mathrm{~N} 1)$ virus is transmittable via droplets $(8.7 \%$, vs. $2.0 \%$ ), while fewer did not know that the $\mathrm{A}(\mathrm{H} 1 \mathrm{~N} 1)$ virus is transmittable via contact with contaminated objects $(16.8 \%$ vs. $21.1 \%)$. Results of the multiple linear regression analysis using total knowledge score as the dependent variable indicated that provision of 
Fig. 2 Temporal changes in perceived susceptibility to infection and confidence in prevention of $\mathrm{H} 1 \mathrm{~N} 1$ infection during the 10-week study period of July 11 to September 13, 2009 , with margins of error at the 0.05 significance level

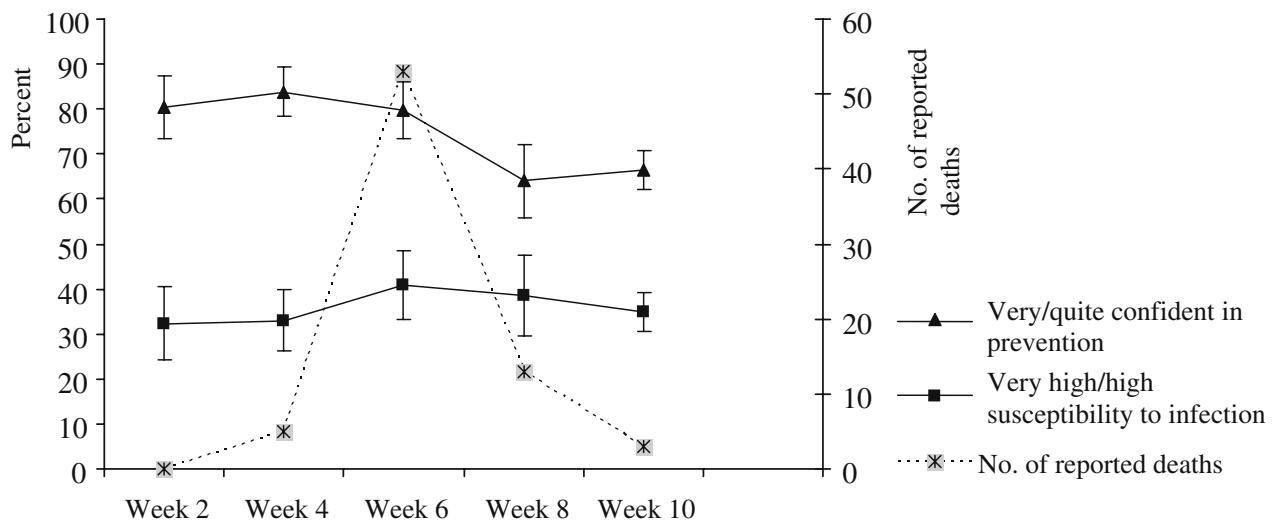

information and education should focus on the male gender, Malay ethnic group, people of lower education and income, and those living in rural areas.

Participants who were female, Malay, employed, of high socio-economic status, and living in urban areas appeared to be more likely to overestimate the severity of $\mathrm{A}(\mathrm{H} 1 \mathrm{~N} 1)$ as they believed the $\mathrm{A}(\mathrm{H} 1 \mathrm{~N} 1)$ infection as often deadly. An overestimation of the severity of $\mathrm{A}(\mathrm{H} 1 \mathrm{~N} 1)$ should be prevented as it may cause unnecessary panic and distress to the community and may lead to interference of a wide range of daily activities. Thus, these specific groups of people may require targeted education $[8,10]$. Despite the overestimation of the severity of $\mathrm{A}(\mathrm{H} 1 \mathrm{~N} 1)$, a high proportion of the participants in this study reported low perceived susceptibility to $\mathrm{A}(\mathrm{H} 1 \mathrm{~N} 1)$ infection, which did not change significantly over the study period, despite the increasing number of deaths. Because perceived susceptibility is expected to begin the process of adoption of preventive behaviors, health authorities and media should stress to the public to continuously adopt precautionary measures to prevent infection even if the number of reported deaths decreases.

Many participants in this study perceived high confidence in preventing themselves and family members from getting the disease. This is of particular concern because an individual may not engage in preventive behavior because of lack of perceived susceptibility to the disease [18]. Of interest, this confidence declined and remained lower even after the number of reported deaths peaked. It has been shown that perceived vulnerability for SARS was significantly associated with perceived threat [19]. Additionally, perceptions of risk and severity were found to influence public's behavioral responses to pandemic influenza $[9,20]$ More research is needed to investigate why the Malaysian public overestimates the severity of this new disease and yet under-perceives its risk of infection, to provide insight into how the health authorities or media should disseminate information to counteract these misconceptions in the future. The findings of our multivariate logistic regression

Table 5 Stigma related to A(H1N1)

\begin{tabular}{|c|c|c|c|c|c|c|}
\hline & \multirow[t]{2}{*}{ Total response $N$} & \multirow[t]{2}{*}{ Yes responses $n(\%)$} & \multicolumn{3}{|c|}{ Yes responses $N(\%)^{\mathrm{a}}$} & \multirow{2}{*}{$\begin{array}{l}\text { Ethnic comparison } \\
P\end{array}$} \\
\hline & & & Malay & Chinese & Indian & \\
\hline $\begin{array}{l}\text { Afraid to be in contact with people } \\
\text { with flu symptoms (e.g., cough, running } \\
\text { nose, sneezing, fever) }\end{array}$ & 1,049 & $638(60.8)$ & $317(72.7)$ & $195(55.4)$ & $126(48.3)$ & $0.000 * * *$ \\
\hline $\begin{array}{l}\text { Afraid to eat outside (e.g., hawker centers, } \\
\text { food courts) }\end{array}$ & 1,049 & $341(32.5)$ & $194(44.5)$ & $69(19.6)$ & $78(29.9)$ & $0.000 * * *$ \\
\hline $\begin{array}{l}\text { Afraid to be in contact with people who } \\
\text { have just returned from overseas }\end{array}$ & 1,049 & $567(54.1)$ & $323(74.1)$ & $134(38.2)$ & $110(42.0)$ & $0.000 * * *$ \\
\hline Afraid of visiting hospitals & 1,050 & $380(36.2)$ & $142(32.6)$ & $149(42.3)$ & $89(34.0)$ & $0.012 *$ \\
\hline Afraid of eating pork and pork products ${ }^{\mathrm{b}}$ & 475 & $34(7.2)$ & Nil & $12(3.6)$ & $22(16.1)$ & $0.000 * * *$ \\
\hline $\begin{array}{l}\text { Afraid of eating birds (chicken) and } \\
\text { bird products }\end{array}$ & 992 & $72(7.3)$ & $39(9.0)$ & $9(2.6)$ & $24(11.2)$ & $0.000 * * *$ \\
\hline
\end{tabular}

Subtotals may vary owing to missing data, and non-responses to questions not applicable to respondents

${ }^{a}$ Percent within ethnic groups

${ }^{\mathrm{b}}$ As Muslims do not eat pork, this question was not asked of the Muslim respondents; comparison was made between Chinese and Indians only

$* P<0.05 ; * * * P<0.001$ 
analyses indicated that education to enhance perceived susceptibility to $\mathrm{A}(\mathrm{H} 1 \mathrm{~N} 1)$ infection should focus on people of older age and people living in suburban areas.

Influenza $\mathrm{A}(\mathrm{H} 1 \mathrm{~N} 1)$ related stigma was prevalent and exhibited differences across ethnic groups. Finding of significant ethnic disparities in $\mathrm{A}(\mathrm{H} 1 \mathrm{~N} 1)$-related stigma suggest further in-depth qualitative exploration on cultural values and beliefs related to each ethnic group. In this study, we also found that perceived severity of A(H1N1) infection was not associated with stigma. Despite widespread information about the control measures in response to the emergence of pandemic influenza $\mathrm{A}(\mathrm{H} 1 \mathrm{~N} 1)$, in particular, near one third of the study participants (including a majority of those that believed $\mathrm{A}(\mathrm{H} 1 \mathrm{~N} 1)$ infection is often deadly) did not fear being in contact with people with influenza symptoms, and approximately $50 \%$ were not afraid to be in contact with people who had just returned from overseas. Although health authorities have repeatedly emphasized that the $\mathrm{A}(\mathrm{H} 1 \mathrm{~N} 1)$ virus is not transmitted by food, a substantial minority avoided eating pork-related products for fear of infection.

Our recently published data on temporal changes in psychobehavioral responses during the H1N1 influenza pandemic [21] showed a noticeable increase in fear of visiting hospitals and fear of eating out in concordance with the escalating number of reported deaths. Similar trends were observed during the SARS outbreak, whereby anxiety levels closely mirrored the daily number of new cases and were strongly associated with the intensity of the outbreak [22]. Moderate fear has been shown as most effective at motivating health-protective behaviors. According to Janis' fear-as-acquired drive model, low levels of fear lead to inaction, moderate levels produce self-protective behavior, whereas high levels result in counterproductive defensive responses [23]. Therefore, health authorities should disseminate accurate information and a realistic view of associated risks to induce a moderate level of fear in order to encourage people to take precautions [21].

There are several limitations of this study. The Cronbach's alpha values of $<0.70$ in this study indicate low consistency, so the scores should be interpreted cautiously. Telephone surveys do not include households without fixed-line telephones, which are more likely to be from socio-economically disadvantaged groups [24]. Furthermore, it may not be possible to generalize our findings to the whole country, as the study sampled from one state (out of 13) and one federal territory (out of three). As a result, the study population had a monthly household income which was higher than the national average of RM3,686 [25] (US $\$ 1=\mathrm{RM} 3.49$, as of Oct 5, 2009), and slightly different proportions of ethnic groups [17].

Despite these methodological caveats, the study has the advantage of a high response rate of $60.0 \%$. Additionally, the issues highlighted by this study are of considerable importance for the understanding of the public's view on the new influenza $\mathrm{A}(\mathrm{H} 1 \mathrm{~N} 1)$ outbreak and have significant implications for information communication efforts. The study can serve as a baseline for future national-level surveys. The study also adds to the relatively scarce knowledge of the new influenza $\mathrm{A}(\mathrm{H} 1 \mathrm{~N} 1)$ in a Malaysian context.

\section{Conclusion}

In summary, some misconceptions and erroneous beliefs about the modes of transmission need to be addressed. High confidence in preventing infection and low perceived susceptibility of infection were reported despite an overestimation of severity of the $\mathrm{A}(\mathrm{H} 1 \mathrm{~N} 1)$ infection. Findings suggest that provision of education and clear information are essential to correct the misconceptions. The perceived susceptibility of infection needs to be increased so that public will take precaution against $\mathrm{A}(\mathrm{H} 1 \mathrm{~N} 1)$ infection and increase health protective behaviors.

Acknowledgement The study is funded by University of Malaya (research grant RG186/10HTM).

Conflict of interest The authors declare no conflict of interest.

\section{References}

1. Sam IC, AbuBakar S. Pandemic influenza A (H1N1) 2009 in Malaysia - the next phase. Med J Malaysia. 2009;64:105-7.

2. Ministry of Health Malaysia Press Release September 13, 2009. Available at: http://A(H1N1).moh.gov.my/kenyataanAkhbar/KPK $\% 2013 \% 20$ Sept\%202009.pdf. Accessed November 10, 2009.

3. Di Giuseppe G, Abbate R, Albano L, Marinelli P, Angelillo IF. A survey of knowledge, attitudes and practices towards avian influenza in an adult population of Italy. BMC Infect Dis. 2008;8:36.

4. Gstraunthaler T, Day R. Avian influenza in the UK: knowledge, risk perception and risk reduction strategies. Br Food J. 2008;110 (2-3):260-70.

5. Blendon RJ, Benson JM, DesRoches CM, Raleigh E, TaylorClark K. The public's response to severe acute respiratory syndrome in Toronto and the United States. Clin Infect Dis. 2004;38(7):925-31.

6. Deurenberg-Yap M, Foo LL, Low YY, Chan SP, Vijaya K, Lee M. The Singaporean response to the SARS outbreak: knowledge sufficiency versus public trust. Health Promot Int. 2005;20 (4):320-6.

7. Leslie T, Billaud J, Mofleh J, Mustafa L, Yingst S. Knowledge, attitudes, and practices regarding avian influenza (H5N1), Afghanistan. Emerg Infect Dis. 2008;14(9):1459-61.

8. Lau JT, Yang X, Pang E, Tsui HY, Wong E, Wing YK. SARSrelated perceptions in Hong Kong. Emerg Infect Dis. 2005;11:417-24.

9. Lau JT, Kim JH, Tsui H, Griffiths S. Perceptions related to human avian influenza and their associations with anticipated psychological and behavioral responses at the onset of outbreak in the Hong 
Kong Chinese general population. Am J Infect Control. 2007;35 (1):38-49.

10. Lau JT, Kim JH, Tsui HY, Griffiths S. Anticipated and current preventive behaviors in response to an anticipated human-tohuman $\mathrm{H} 5 \mathrm{~N} 1$ epidemic in the Hong Kong Chinese general population. BMC Infect Dis. 2007;7:18.

11. Lau JT, Yang X, Tsui H, Kim JH. Monitoring community responses to the SARS epidemic in Hong Kong: from day 10 to day 62. J Epidemiol Community Health. 2003;57:864-70.

12. Lau JT, Tsui H, Lau M, Yang X. SARS transmission, risk factors, and prevention in Hong Kong. Emerg Infect Dis. 2004;10(4):587-92.

13. Peltz R, Avisar-Shohat G, Bar-Dayan Y. Differences in public emotions, interest, sense of knowledge and compliance between the affected area and the nationwide general population during the first phase of a bird flu outbreak in Israel. J Infect. 2007;55 (6):545-50.

14. Lau JT, Griffiths S, Choi KC, Tsui HY. Widespread public misconception in the early phase of the $\mathrm{A}(\mathrm{H} 1 \mathrm{~N} 1)$ influenza epidemic. J Infect. 2009;59(2):122-7.

15. Rubin GJ, Amlôt R, Page L, Wessely S. Public perceptions, anxiety, and behaviour change in relation to the swine flu outbreak: cross sectional telephone survey. BMJ. 2009;339:b2651.

16. Goodwin R, Gaines SO, Myers L, Neeto F. Initial psychological responses to swine flu. Int J Behav Med 2010 doi: 10.1007/ s12529-010-9083-z

17. Social Statistics Bulletin Malaysia 2008. Department of Statistics, Malaysia.
18. Rosenstock IM, Kirscht JP. The health belief model and personal health behavior. Health Educ Monogr. 1974;2:470-3.

19. de Zwart O, Veldhuijzen IK, Elam G, Aro AR, Abraham T, Bishop GD, et al. Perceived threat, risk perception, and efficacy beliefs related to SARS and other (emerging) infectious diseases: results of an international survey. Int J Behav Med. 2009;16:30-40.

20. Leppin A, Aro AR. Risk perception related to SARS and avian influenza: theoretical foundations of current behavioral research. Int J Behav Med. 2009;16:7-29.

21. Wong LP, Sam IC. Temporal changes in psychobehavioral responses during the 2009 H1N1 influenza pandemic. Prev Med. 2010;51:92-3.

22. Leung GM, Ho LM, Chan SK, Ho SY, Bacon-Shone J, et al. Longitudinal assessment of community psychobehavioral responses during and after the 2003 outbreak of severe acute respiratory syndrome in Hong Kong. Clin Infect Dis. 2005;40:1713-20.

23. Janis IL. Effects of fear arousal on attitude change: recent developments in theory and experimental research. In: Berkowitz L, editor. Advances in experimental social psychology (Vol. 3). New York: Academic; 1967. p. 166-225.

24. Boland M, Sweeney MR, Scallan E, Harrington M, Staines A. Emerging advantages and drawbacks of telephone surveying in public health research in Ireland and the U.K. BMC Public Health. 2006;6:208.

25. Economic Planning Unit (EPU). Mid-term review of the Ninth Malaysia Plan 2006-2010. Kuala Lumpur, Malaysia: Economic Planning Unit, Prime Minister's Department; 2008. 